\title{
PENGARUH PENAMBAHAN ZIRKONIUM OKSIDA PADA BAHAN BASIS GIGI TIRUAN RESIN AKRILIK POLIMERISASI PANAS TERHADAP KEKUATAN IMPAK DAN TRANSVERSAL
}

\author{
Eddy Dahar, Sri Handayani \\ Departemen Prostodonsia Fakultas Kedokteran Gigi, Universitas Sumatera Utara \\ JL. Alumni No.2 Kampus USU Medan 20155 \\ Email: deanritonga09@gmail.com
}

\begin{abstract}
Abstrak
Resin akrilik yang dipolimerisasi panas (RAPP) telah banyak digunakan sebagai bahan dasar gigi tiruan karena memiliki kelebihan seperti keadaan biokompatibel, jauh lebih estetis, mudah diproses, tidak memerlukan keahlian laboratorium untuk memperbaiki dan harganya relatif murah. Namun, RAPP adalah bahan dasar gigi tiruan yang mudah patah karena kekuatan impak dan transversal yang rendah. Kekuatan impak dan transversal dapat ditingkatkan dengan penambahan bahan penguat nanopartikel zirkonium oksida $\left(\mathrm{ZrO}_{2}\right)$. Penelitian ini bertujuan untuk mengetahui pengaruh penambahan nanopartikel $\mathrm{ZrO}_{2}$ konsentrasi 5\%, $6 \%$ dan $7 \%$ pada bahan basis gigi tiruan RAPP terhadap kekuatan impak dan transversal. Nanopartikel $\mathrm{ZrO}_{2}$ dilapisi dengan lapisan trimetoksisilipropilmetrilat (TMSPM) sebelum disonikasi dalam monomer ( MMA) dengan konsentrasi yang berbeda 5\%,6\% dan 7\% menurut beratnya. Rancangan penelitian ini adalah eksperimental laboratoris. Sampel penelitian ini adalah bentuk persegi panjang dengan ukuran batang uji 80 $\mathrm{mm} \times 10 \mathrm{~mm}$ x $4 \mathrm{~mm}$ untuk uji kekuatan impak dan $65 \mathrm{~mm}$ x $10 \mathrm{~mm}$ x 2,5 mm untuk uji kekuatan transversal. Total sampel sebanyak 48 sampel terdiri dari 24 sampel untuk kelompok uji kekuatan impak dan 24 sampel untuk kelompok uji kekuatan transversal. Setiap sampel diuji Amslerotto Walpret Werke GMBH, Jerman untuk uji kekuatan Impak dan Electronic System Universal Testing Machine, Jepang untuk uji kekuatan transversal. Kesimpulan penambahan nanopartikel $\mathrm{ZrO}_{2}$ konsentrasi $5 \%$ dan $6 \%$ pada bahan basis gigi tiruan dari RAPP dapat meningkatkan kekuatan impak dan transversal namun dapat menurunkan kekuatan impak dan transversal dengan penambahan nanopartikel $\mathrm{ZrO}_{2} 7 \%$ pada bahan basis gigi tiruan RAPP.
\end{abstract}

Kata kunci : poli (methylmethacylate), nanopartikel oksida zirkonium, nano komposit, kekuatan impak, kekuatan transversal

\section{PENDAHULUAN}

Tahun 1937 Wright W menemukan polimetilmetakrilat yang disebut juga resin akrilik. ${ }^{1,2}$ Sejak pertengahan tahun 1940, resin akrilik sudah banyak digunakan dalam bidang kedokteran gigi untuk berbagai keperluan, diantaranya untuk pelapis estetik, splinting, bahan pembuat anasir gigi tiruan, piranti ortodontik, bahan reparasi dan bahan basis gigi tiruan. Resin ini terdiri dari cairan yang mengandung metil metakrilat tidak terpolimer dan bubuk yang mengandung resin (polimetilmetakrilat). Resin akrilik polimerisasi panas (RAPP) adalah bahan basis gigi tiruan yang proses polimerisasinya menggunakan energi termal atau energi panas. Energi termal yang dibutuhkan untuk proses polimerisasi RAPP dapat diperoleh dari waterbath atau microwave.

RAPP merupakan bahan basis gigi tiruan yang sering digunakan oleh dokter gigi. Bahan basis gigi tiruan ini memiliki nilai estetik yang baik karena memiliki kualitas warna yang hampir sama dengan jaringan rongga mulut. $^{2}$ Penelitian pada tahun 1946 menyatakan bahwa 95\% bahan basis gigi tiruan terbuat dari RAPP, meskipun demikian RAPP memiliki kelemahan diantaranya adalah kekuatan impak, dan transversal yang rendah.

Kekuatan impak adalah kemampuan dari suatu bahan untuk menerima beban benturan sampai bahan tersebut patah. Dalam kehidupan sehari-hari kekuatan impak pada penggunaan gigi tiruan dikaitkan dengan tekanan tiba-tiba saat gigi tiruan terjatuh dan terbentur pada permukaan yang keras. ${ }^{2-4}$ Kekuatan transversal adalah kemampuan dari suatu bahan di dalam menerima beban yang ditambah secara beraturan sampai bahan tersebut patah. Kekuatan transversal inilah yang terjadi terus menerus didalam rongga mulut saat pengunyahan sehingga menyebabkan fraktur basis gigi tiruan., 3,4

Salah satu upaya untuk meningkatkan kekuatan impak dan transversal dengan menambahkan bahan penguat ke dalam RAPP. Terdapat beberapa bahan penguat berupa logam, serat maupun kimia. Bahan logam yang dapat ditambahkan ke dalam resin akrilik ialah logam 
yang berbentuk kawat, plat dan anyaman, tetapi bahan ini jarang digunakan karena akan mengurangi estetik gigi tiruan. ${ }^{6,7}$ Bahan serat yang dapat ditambahkan ke dalam resin akrilik antara lain serat kaca, serat polietilen, serat aramid dan serat karbon. ${ }^{8}$ Bahan kimia yang dapat digunakan sebagai bahan penguat berupa cross-lingkingagent, rubber particles dan filler kimia. Penemuan terbaru filler kimia berupa nanoteknologi digunakan dalam perkembangan bidang prostodonsia dengan tujuan peningkatan kekuatan dan material kedokteran gigi. Beberapa bahan penguat jenis filler kimia yang digunakan sebagai bahan penguat basis gigi tiruan RAPP adalah $\mathrm{TiO}_{2}$, $\mathrm{ZrO}_{2}, \mathrm{Al}_{2} \mathrm{O}_{3}, \mathrm{BaTiO}_{3}{ }^{2,4,5}$

$\mathrm{ZrO}_{2}$ (Zirkonium Oksida) merupakan nanopartikel yang sekarang tengah dikembangkan untuk digunakan sebagai bahan penguat basis gigi tiruan RAPP, karena berbagai kelebihan yang dimiliki $\mathrm{ZrO}_{2}$ dibanding dengan bahan penguat lain seperti memiliki kekuatan dan kekerasan yang tinggi, biokompatibilitas, tahan terhadap abrasi tidak bersifat toksik, tidak menghantarkan listrik, konduktifits termal yang rendah dan kekuatan termal lebih baik dari pada aluminia serta tahan terhadap korosi. Nanopartikel $\mathrm{ZrO}_{2}$ dapat menahan tekanan sekitar 2000 $\mathrm{MPa}$.

Penelitian Ihab NS, dkk. (2011) menyatakan bahwa penambahan nanopartikel $\mathrm{ZrO}_{2}$ dengan konsentrasi $2 \%, 3 \%$, 5\% dan $7 \%$ yang paling baik meningkatkan kekuatan impak dan transversal adalah nanopartikel $\mathrm{ZrO}_{2}$ dengan konsentrasi $5 \%$ dan yang paling buruk adalah nanopartikel $\mathrm{ZrO}_{2}$ dengan konsentrasi $7 \%$. ${ }^{4}$ Penelitian lain dikemukakan Mohammed, dkk. (2014) mengenai peningkatan kekuatan transversal dengan penambahan nanopartikel $\mathrm{ZrO}_{2}$ dengan beberapa konsentrasi, yaitu $1.5 \%, 3 \%$, 5\%, dan $7 \%$. Hasil penelitian menunjukkan bahwa peningkatan kekuatan transversal tertinggi yaitu dengan penambahan nanopartikel $\mathrm{ZrO}_{2} 7 \%$, diikuti oleh konsentrasi $5 \%, 3 \%$, dan yang terendah $1,5 \% .{ }^{13}$ Penelitian tersebut bertentangan dengan penelitian yang dilakukan oleh Hussein KH, dkk. (2015) menguji beberapa kelompok konsentrasi nanopartikel $\mathrm{ZrO}_{2}$ terhadap kekuatan impak transversal RAPP yang yang terdiri dari beberapa kelompok. Kelompok pertama merupakan kelompok kontrol tanpa penambahan nanopartikel $\mathrm{ZrO}_{2}$, kelompok kedua dengan penambahan nanopartikel $\mathrm{ZrO}_{2} \quad 3 \%$, kelompok ketiga dengan penambahan nanopartikel $\mathrm{ZrO}_{2}$ $5 \%$, dan kelompok keempat dengan penambahan nanopartikel $\mathrm{ZrO}_{2} 7 \%$. Hasil penelitian menunjukkan terjadi peningkatan nilai kekuatan transversal yang signifikan pada penambahan nanopartikel $\mathrm{ZrO}_{2}$ dengan konsentrasi $3 \%$ dan 5\%, namun terjadi penurunan kekuatan pada penambahan nanopartikel $\mathrm{ZrO}_{2}$ dengan konsentrasi 7\% dibanding kelompok kontrol. Nanopartikel $\mathrm{ZrO}_{2}$ yang ditambakan ditambahkan pada RAPP untuk basis gigi tiruan bertujuan untuk meningkatkan kekuatan dengan bahan penyatu berupa silane coupling agent yang mengandung (trimethoxyprophylsilylmethacrylate). ${ }^{13-15}$ Dari hasil penelitian-penelitian sebelumnya menunjukkan bahwa penambahan nanopartikel $\mathrm{ZrO}_{2}$ dengan konsentrasi 5\% ke dalam bahan basis gigi tiruan RAPP hasil kekuatan impak dan transversal meningkat, tetapi penambahan nanopartikel $\mathrm{ZrO}_{2}$ konsentrasi $7 \%$ ke dalam bahan basis gigi tiruan RAPP meningkatkan kekuatan impak dan transversal menurun serta hasil konsentrasi 5\% dan 7\% menunjukkan hasil yang berbeda-beda. Sedangkan penambahan nanopartikel $\mathrm{ZrO}_{2}$ dengan konsentrasi $6 \%$ ke dalam basis gigi tiruan RAPP untuk mengetahui apakah dengan penambahan konsentrasi $6 \%$ hasil penelitian dapat meningkatkan atau menurunkan kekuatan impak dan transversal basis gigi tiruan RAPP

Berdasarkan uraian tersebut, maka peneliti merasa perlu dilakukan penelitian untuk melihat pengaruh penambahan nanopartikel $\mathrm{ZrO}_{2}$ dengan konsentrasi $5 \%$, $6 \%$ dan $7 \%$ terhadap kekuatan impak dan transversal basis gigi tiruan RAPP dengan harapan dapat meningkatkan kekuatan impak dan transversal bahan basis gigi tiruan RAPP.

\section{BAHAN DAN METODE}

Rancangan penelitian yang digunakan dalam penelitian ini adalah eksperimental laboratoris. Sampel berasal dari model induk yang terbuat dari stainless steel dengan ukuran $80 \mathrm{~mm}$ x $10 \mathrm{~mm}$ x $4 \mathrm{~mm}$ (ISO No 1567) untuk kekuatan impak dan ukuran $65 \mathrm{~mm}$ x $10 \mathrm{~mm}$ x 2,5 mm (ISO No 1567) untuk kekuatan transversal. Jumlah keseluruhan sampel adalah 48 sampel yang terdiri dari 24 sampel uji kekuatan impak dan 24 sampel uji kekuatan transversal. Sampel dibagi dalam 4 kelompok (kelompok A: RAPP tanpa penambahan $\mathrm{ZrO}_{2}$, kelompok B: RAPP dengan penambahan nanopartikel $\mathrm{ZrO}_{2}$ konsentrasi 5\%, kelompok C: RAPP dengan penambahan nanopartikel $\mathrm{ZrO}_{2}$ konsentrasi $6 \%$ dan kelompok D: RAPP dengan penambahan nanopartikel $\mathrm{ZrO}_{2}$ konsentrasi $7 \%$ ).

Nanopartikel $\mathrm{ZrO}_{2}$ terlebih dahulu dilakukan silanisasi untuk meningkatkan adhesi antara nanopartikel $\mathrm{ZrO}_{2}$ dan RAPP dengan cara :

1) 30 gr nanopartikel $\mathrm{ZrO}_{2}$ dimasukkan ke dalam tabung erlenmeyer yang berisi $200 \mathrm{ml}$ etanol murni yang digunakan sebagai pelarut. Selanjutnya tabung erlenmeyer dimasukkan ke dalam sonikator pada temperatur ruang selama 20 menit.

2) Tabung erlenmeyer digetarkan selama 20 menit pada suhu ruang menggunakan magnetic stirrer sehingga nanopartikel $\mathrm{ZrO}_{2}$ dan etanol tercampur homogen. Tambahkan silane coupling agent sebanyak 1,5 ml (5\% dari nanopartikel $\mathrm{ZrO}_{2}$ ) ke dalam campuran nanopartikel $\mathrm{ZrO}_{2}$ dan etanol menggunakan syringe steril kemudian getarkan dengan getaran $250 \mathrm{rpm}$ selama 60 menit.

3) Campuran dituangkan ke dalam wadah tertutup dan dibiarkan selama 2 hari pada suhu ruang agar zat yang dilarutkan silane coupling agent dapat meresap sempurna pada permukaan $\mathrm{ZrO}_{2}$. Etanol yang tercampur pada nanopartikel $\mathrm{ZrO}_{2}$ diuapkan dengan menggunakan rotary evaporator dengan suhu $60^{\circ} \mathrm{C}$ dan kecepatan $150 \mathrm{rpm}$ selama 30 menit untuk memisahkan pelarut etanol dan campuran silane coupling agent yang telah menyatu dengan $\mathrm{ZrO}_{2}$.

4) Alat vacuum buchner digunakan untuk menghilangkan sisa etanol dan silane coupling agent yang tersisa. 
Selanjutnya nanopartikel $\mathrm{ZrO}_{2}$ yang sudah di silanisasi dikeringkan di dalam oven pada suhu $60^{\circ} \mathrm{C}$ selama 20 jam, kemudian dikeluarkan dari oven. Selanjutnya nanopartikel $\mathrm{ZrO}_{2}$ diproses menggunakan alat sonikator dengan kecepatan $250 \mathrm{rpm}$ selama 3 menit untuk memecah partikel yang menggumpal kemudian disonikasi kembali selama 3 menit untuk mecapurkan monomer dan $\mathrm{ZrO}_{2}$ agar menjadi nanopartikel kembali. ${ }^{6,7}$

Pengisian akrilik pada mold:

a) Pembuatan sampel RAPP tanpa bahan penguat nanopartikel $\mathrm{ZrO}_{2}$

Polimer dan monomer disiapkan di dalam pot porselen dengan perbandingan 12 gr bubuk : $6 \mathrm{ml}$ cairan untuk uji impak lalu diaduk hingga homogen. Perbandingan polimer dan monomer di dalam pot porselen dengan perbandingan 9 gr bubuk : 4,5 cairan untuk uji trasnversal lalu diaduk hingga homogen.

b). Pembuatan sampel RAPP dengan penambahan nopartikel $\mathrm{ZrO}_{2}$ Konsentrasi $5 \%$

Nanopartikel $\mathrm{ZrO}_{2}$ yang telah disilanisasi ditimbang sebanyak 0,9 gr untuk 1 buah kuvet yang terdiri dari 3 mold sampel kekuatan impak dan 0,68 gr untuk 1 buah kuvet yang terdiri dari 3 mold sampel kekuatan transversal. Perhitungan tersebut setara dengan 5\% dari total berat polimer dan monomer. Maka perbandingan $\mathrm{ZrO}_{2}$ : polimer : monomer untuk pengisian mold kekuatan impak adalah 0,9 gr : 11,1 gr : $6 \mathrm{ml}$ dan untuk mold kekuatan transversal adalah 0,68 gr : 8,32 gr : $4.5 \mathrm{ml}$.

c) Pembuatan sampel RAPP dengan penambahan nanopartikel $\mathrm{ZrO}_{2}$ konsentrasi $6 \%$

Nanopartikel $\mathrm{ZrO}_{2}$ ditimbang sebanyak $1,08 \mathrm{gr}$ untuk 1 buah kuvet sampel kekuatan impak dan 0,81 gr untuk 1 buah kuvet sampel kekuatan transversal. Perhitungan tersebut setara dengan 6\% dari total berat polimer dan monomer. Maka perbandingan $\mathrm{ZrO}_{2}$ : polimer : monomer untuk pengisian mold kekuatan impak adalah 1,08 gr : 10,92 gr : $6 \mathrm{ml}$ dan mold kekuatan transversal adalah $0,81 \mathrm{gr}: 8,19 \mathrm{gr}: 4,5 \mathrm{ml}$.

d) Pembuatan sampel RAPP dengan penambahan nanopartikel $\mathrm{ZrO}_{2}$ konsentrasi $7 \%$

Nanopartikel $\mathrm{ZrO}_{2}$ ditimbang sebanyak 1,26 gr untuk 1 buah kuvet sampel kekuatan impak dan 0,945 gr untuk 1 buah kuvet sampel kekuatan transversal. Perhitungan tersebut setara dengan 7\% dari total berat polimer dan monomer. Maka perbandingan $\mathrm{ZrO}_{2}$ : polimer : monomer untuk pengisian mold kekuatan impak adalah 1 , 26 gr : 10, 74 gr : $6 \mathrm{ml}$ dan mold kekuatan transversal adalah $0,96 \mathrm{gr}: 8,04 \mathrm{gr}: 4,5 \mathrm{ml}$ di dalam pot akrilik dan diaduk menggunakan spatula semen hingga homogen.

5) Adonan dimasukkan ke dalam mold dan ditutup dengan plastik selopan kemudian kuvet atas dipasangkan, kuvet ditekan perlahan-lahan dengan pres hidrolik mencapai 1000 psi, lalu kuvet dibuka. Akrilik yang berlebih dipotong dengan lekron.

6) Kuvet ditutup kembali, kemudian pres dengan tekanan 1500 psi.
7) Baut kuvet dipasang untuk mempertahankan kuvet atas dan kuvet bawah agar beradaptasi dengan baik dan dibiarkan selama 15 menit. Waktu kuring diatur pada suhu $70^{\circ} \mathrm{C}$ selama 30 menit, kemudian dinaikkan menjadi $100^{\circ} \mathrm{C}$ selama 90 menit. Kuvet dibiarkan dingin di dalam waterbath selama 30 menit, kemudian kuvet diletakkan di bawah air mengalir selama 15 menit.. Sampel dikeluarkan dari kuvet, kemudian dirapikan untuk menghilangkan bagian yang berlebih dan tajam dengan menggunakan bur fraser kemudian sampel dihaluskan permukaannya dengan kertas pasir ukuran 600 yang dipasangkan pada rotary grinder dengan air mengalir selama 3 menit dengan kecepatan $500 \mathrm{rpm}$. Kemudian pemolesan dilakukan dengan menggunakan Scotch-Brite brush yang dipasangkan pada polishing motor dengan kecepatan $500 \mathrm{rpm}$ selama 5 menit. Sampel diukur menggunakan kaliper untuk memastikan ukuran sampel sesuai dengan ukuran yang ditetapkan dan sebelum dilakukan pengujian sampel terlebih dahulu direndam dalam akuades selama 48 jam untuk menghilangkan titik jenuh matriks resin dan monomer sisa. Setiap sampel dilakukan pengujian kekuatan impak dan transversal menggunakan alat Amslerotto Walpret Werke GMBH, Germany dan Torsee's Electronic System Universal Testing Machine, Japan. Analisis data dilakukan dengan uji Univarian untuk mengetahui nilai rerata dan standar deviasi kekuatan impak dan transversal basis gigi tiruan RAPP, Sedangakan uji Anova satu arah untuk mengetahui pengaruh penambahan nanopartikel $\mathrm{ZrO}_{2}$ dengan konsentrasi 5\%, 6\% dan 7\% terhadap kekuatan impak dan transversal basis gigi tiruan RAPP, dan uji LSD untuk mengetahui perbedaan pengaruh penambahan nanopartikel $\mathrm{ZrO}_{2}$ dengan konsentrasi $5 \%$, 6\% dan $7 \%$ terhadap kekuatan impak dan transversal basis gigi tiruan RAPP.

\section{HASIL}

Hasil penelitian menunjukkan bahwa nilai kekuatan impak terkecil pada kelompok A adalah 6,00 x $10^{-3} \mathrm{~J} / \mathrm{mm}^{2}$, sedangkan kekuatan terbesar adalah $8,50 \times 10^{-3}$ $\mathrm{J} / \mathrm{mm}^{2}$, dengan nilai rerata dan standar deviasi adalah 6,91 x $10^{-3} \pm 0,98 \times 10^{-3} \mathrm{~J} / \mathrm{mm}^{2}$. Nilai kekuatan impak terkecil pada kelompok B adalah $11,25 \times 10^{-3} \mathrm{~J} / \mathrm{mm}^{2}$, dan nilai kekuatan terbesar adalah $13,50 \times 10^{-3} \mathrm{~J} / \mathrm{mm}^{2}$, dengan nilai rerata dan standar deviasi adalah $12,37 \times 10^{-3} \pm 0,86 \times 10^{-3}$ $\mathrm{J} / \mathrm{mm}^{2}$. Nilai kekuatan impak terkecil pada kelompok C adalah $7,75 \times 10^{-3} \mathrm{~J} / \mathrm{mm}^{2}$, dan nilai kekuatan terbesar adalah $9,75 \times 10^{-3} \mathrm{~J} / \mathrm{mm}^{2}$, dengan nilai rerata dan standar deviasi adalah $8,70 \times 10^{-3} \pm 0,84 \times 10^{-3} \mathrm{~J} / \mathrm{mm}^{2}$ Nilai kekuatan impak terkecil pada kelompok $\mathrm{C}$ adalah 4,50 $\mathrm{x}$ $10^{-3} \mathrm{~J} / \mathrm{mm}^{2}$, dan niali kekuatan terbesar adalah $6,50 \times 10^{-3}$ $\mathrm{J} / \mathrm{mm}^{2}$, dengan nilai rerata dan standar deviasi adalah 5,08 x $10^{-3} \pm 0,78 \times 10^{-3} \mathrm{~J} / \mathrm{mm}^{2}$. (Tabel 1 ) 
Tabel 1. Nilai kekuatan impak bahan basis gigi tiruan RAPP tanpa dan dengan penambahan nanopartikel $\mathrm{ZrO}_{2}$ konsentrasi 5\%, 6\% dan 7\%

\begin{tabular}{|c|c|c|c|c|}
\hline \multirow{2}{*}{ No } & & \multicolumn{3}{|c|}{ Kekuatan Impak RAPP $\left(\mathrm{mm}^{2} 10^{-3}\right)$} \\
\cline { 2 - 5 } & Kel A & Kel B & Kel C & Kel D \\
\hline 1 & 6,25 & 11,75 & 9,25 & $4,50^{* *}$ \\
\hline 2 & 6,50 & $13,25^{*}$ & $9,75^{*}$ & 4,75 \\
\hline 3 & $6,00^{* *}$ & 12,25 & $7,75^{* *}$ & $6,50^{*}$ \\
\hline 4 & 7,75 & $11,25^{* *}$ & 8,50 & 4,75 \\
\hline 5 & 6,50 & 13,50 & 9,25 & $4,50 * *$ \\
\hline 6 & $8,50 *$ & 12,25 & $7,75^{* *}$ & 5,50 \\
\hline $\bar{X} \pm$ & $6,916 \pm$ & $12,3750 \pm$ & $8,7083 \pm$ & $5,0833 \pm$ \\
SD & 0,9831 & 0,86241 & 0,84286 & 0,78528 \\
\hline
\end{tabular}

Keterangan: * nilai terbesar

$* *$ nilai terkecil

$\bar{X}=$ nilai rerata

$\mathrm{SD}=$ Standar Deviasi

Nilai rerata dan standar deviasi yang kekuatan transversal terkecil pada kelompok A adalah 894,00 $\mathrm{kg} / \mathrm{cm}^{2}$, dan nilai kekuatan terbesar adalah 985,00 kg/ $\mathrm{cm}^{2}$, dengan nilai rerata dan standar deviasi adalah 942,00 \pm $33.99 \mathrm{~kg} / \mathrm{cm}^{2}$. Nilai kekuatan transversal terkecil pada kelompok B adalah $1136,40 \mathrm{~kg} / \mathrm{cm}^{2}$, dan nilai kekuatan terbesar adalah $1320,00 \mathrm{~kg} / \mathrm{cm}^{2}$, dengan nilai rerata dan standar deviasi adalah $1242.40 \pm 69.99 \mathrm{~kg} / \mathrm{cm}^{2}$. Nilai kekuatan transversal terkecil pada kelompok $\mathrm{C}$ adalah $894,00 \mathrm{~kg} / \mathrm{cm}^{2}$, dan nilai kekuatan terbesar adalah 1044,00 $\mathrm{kg} / \mathrm{cm}^{2}$, dengan nilai rerata dan standar deviasi adalah $967.80 \pm 58.70 \mathrm{~kg} / \mathrm{cm}^{2}$. Nilai kekuatan transversal terkecil pada kelompok D adalah $840,00 \mathrm{~kg} / \mathrm{cm}^{2}$, dan nilai kekuatan terbesar adalah $916,80 \mathrm{~kg} / \mathrm{cm}^{2}$, dengan nilai rerata dan standar deviasi adalah $870.00 \pm 44.51 \mathrm{~kg} / \mathrm{cm}^{2}$. (Tabel 2)

Tabel 2. Nilai kekuatan transversal bahan basis gigi tiruan RAPP tanpa dan dengan penambahan nanopartikel $\mathrm{ZrO}_{2}$ konsentrasi 5\%,6\% dan $7 \%$.

\begin{tabular}{|c|c|c|c|c|}
\hline \multirow{2}{*}{ No } & & \multicolumn{3}{|c|}{ Kekuatan Transversal RAPP } \\
$\left(\mathrm{Kg} / \mathrm{cm}^{2}\right)$
\end{tabular}

Keterangan: * nilai terbesar

$* *$ nilai terkecil

$\bar{X}=$ nilai rerata

$\mathrm{SD}=$ Standar Deviasi

Pengaruh penambahan nanopartikel $\mathrm{ZrO}_{2}$ konsentrasi $5 \%$, 6\% dan $7 \%$ pada bahan basis gigi tiruan RAPP terhadap kekuatan impak dan transversal dianalisis dengan menggunakan uji Anova satu arah dan diperoleh nilai $\mathrm{p}=0,0001(\mathrm{p}>0,05)$. (Tabel 3) dan (Tabel 4).

Tabel 3. Pengaruh penambahan nanopartikel $\mathrm{ZrO}_{2}$ konsentrasi 5\%,6\% dan 7\% terhadap kekuatan impak basis gigi tiruan RAPP

\begin{tabular}{|c|r|c|c|}
\hline \multirow{2}{*}{ Kelompok } & \multicolumn{3}{|c|}{ Kekuatan impak RAPP $\left({\left.\mathrm{x} 10^{-3}\right)}_{\mathrm{J} / \mathrm{mm}^{2}}\right.$} \\
\cline { 2 - 3 } & $\mathrm{n}$ & $\bar{X} \pm \mathrm{SD}$ & $\mathrm{P}$ \\
\hline A & 6 & $6,9167 \pm 0,9831$ & \\
\hline B & 6 & $12,3750 \pm 0,86241$ & \multirow{2}{*}{0,0001} \\
\hline C & 6 & $8,7083 \pm 0,84268$ & \\
\hline D & 6 & $5,0833 \pm 0,78528$ & \\
\hline
\end{tabular}

Tabel 4. Pengaruh penambahan nanopartikel $\mathrm{ZrO}_{2}$ konsentrasi 5\%, 6\% dan 7\% terhadap kekuatan transversal basis gigi tiruan RAPP

\begin{tabular}{|c|c|c|c|}
\hline \multirow{2}{*}{ Kelompok } & \multicolumn{3}{|c|}{ Kekuatan transversal RAPP $\left(\mathrm{Kg} / \mathrm{cm}^{2}\right)$} \\
\cline { 2 - 3 } & $\mathrm{n}$ & $\bar{X} \pm$ SD & P \\
\hline A & 6 & $942,000 \pm 33,99$ & \multirow{2}{*}{0,0001} \\
\hline B & 6 & $1242,400 \pm 69,99$ & \\
\hline C & 6 & $967,8000 \pm 58,70$ & \\
\hline D & 6 & $870,0000 \pm 44,51$ & \\
\hline
\end{tabular}

Hal ini berarti ada pengaruh penambahan nanopartikel $\mathrm{ZrO}_{2}$ pada bahan basis gigi tiruan RAPP terhadap kekuatan impak dan transversal $(\mathrm{p}=0,0001)$.

Perbedaan pengaruh penambahan nanopartikel $\mathrm{ZrO}_{2}$ konsentrasi 5\%, 6\% dan $7 \%$ pada bahan basis gigi tiruan RAPP terhadap kekuatan impak dan transversal dianalisis dengan uji LSD ( $\mathrm{p}<0,005)$. (Tabel 5) dan (Tabel 6)

Tabel 5. Perbedaan pengaruh penambahan nanopartikel $\mathrm{ZrO}_{2}$ konsentrasi 5\%, 6\% dan 7\% terhadap kekuatan impak bahan basis gigi tiruan RAPP

\begin{tabular}{|c|c|c|}
\hline \multicolumn{2}{|c|}{ Kelompok } & P \\
\hline \multirow{2}{*}{$\mathrm{B}$} & $\mathrm{C}$ & 0,0001 \\
\cline { 2 - 3 } & $\mathrm{D}$ & 0,0001 \\
\hline \multirow{2}{*}{$\mathrm{C}$} & $\mathrm{B}$ & 0,0001 \\
\cline { 2 - 3 } & $\mathrm{D}$ & 0,0001 \\
\hline \multirow{2}{*}{$\mathrm{D}$} & $\mathrm{B}$ & 0,0001 \\
\cline { 2 - 3 } & $\mathrm{C}$ & 0,0001 \\
\hline
\end{tabular}

*signifikan

Tabel 6. Perbedaan pengaruh penambahan nanopartikel $\mathrm{ZrO}_{2}$ konsentrasi 5\%, 6\% dan $7 \%$ terhadap kekuatan transversal bahan basis gigi tiruan RAPP

\begin{tabular}{|c|c|c|}
\hline \multicolumn{2}{|c|}{ Kelompok } & $\mathrm{P}$ \\
\hline \multirow{2}{*}{$\mathrm{B}$} & $\mathrm{C}$ & 0,0001 \\
\cline { 2 - 3 } & $\mathrm{D}$ & 0,0001 \\
\hline \multirow{2}{*}{$\mathrm{C}$} & $\mathrm{B}$ & 0,0001 \\
\cline { 2 - 3 } & $\mathrm{D}$ & 0,005 \\
\hline \multirow{2}{*}{$\mathrm{D}$} & $\mathrm{B}$ & 0,0001 \\
\cline { 2 - 3 } & $\mathrm{C}$ & 0,001 \\
\hline
\end{tabular}

\footnotetext{
*signifikan
} 
Hal ini berarti ada perbedaan pengaruh penambahan nanopartikel $\mathrm{ZrO}_{2}$ pada bahan basis gigi tiruan RAPP terhadap kekuatan impak dan transversal ( $\mathrm{p}<$ 0,005).

\section{PEMBAHASAN}

Hasil penelitian didapatkan nilai kekuatan impak dan transversal bervariasi, hal ini kemungkinan dapat disebabkan oleh beberapa faktor diantaranya proses pembuatan sampel yang tidak dapat dikendalikan, salah satunya dikarenakan pencampuran antara monomer dan polimer bahan basis gigi tiruan RAPP tidak dilakukan secara bersamaan untuk semua sampel dan teknik pengadukan yang dilakukan secara manual menyebabkan kecepatan pengadukannya tidak dapat dikendalikan dengan sempurna. Ferasima R. dkk (2013) menyatakan teknik pengadukan yang manual dapat menyebabkan terperangkapnya udara di dalam matriks bahan basis gigi tiruan RAPP sehingga dapat terjadi porositas yang dapat memengaruhi kekuatan impak dan transversal bahan basis gigi tiuan RAPP. ${ }^{15}$ Adanya porositas internal yang tidak dapat dilihat dapat memengaruhi kekuatan impak dan transversal yang dihasilkan. Hal ini disebabkan oleh masuknya udara selama prosedur pengadukan yang dilakukan secara manual sehingga semakin banyak porositas internal yang dapat menurunkan kekuatan impak dan transversal. Seharusnya pengadukan bahan basis gigi tiruan menggunakan alat vacuum mixer. Vojvodic D. dkk (2008) menyarankan penggunaaan alat vacuum mixer saat pengadukan bahan basis gigi tiruan RAPP agar tidak ada udara yang terperengkap dalam matriks polimer. ${ }^{16}$ Faktor lain yang menyebabkan bervariasinya nilai kekuatan impak yang dihasilkan setiap sampel pada penelitian ini adalah adanya kesulitan saat memegang dan menekan sampel pada alat rotary grinder yang dapat mempengaruhi permukaan sampel sehingga menyebabkan nilai kekuatan impak dan transversal yang berbeda pada setiap sampel. ${ }^{2}$

Hasil yang diperoleh pada penelitian ini hampir sama dengan hasil penelitian yang dilakukan oleh Ihab NS, dkk. (2011) yang menyatakan bahwa penambahan nanopartikel $\mathrm{ZrO}_{2}$ dengan konsentrasi 2\%, 3\%, 5\% dan 7\% yang paling baik meningkatkan kekuatan impak dan transversal adalah penambahan nanopartikel $\mathrm{ZrO}_{2}$ konsentrasi $5 \%$ dan yang paling buruk adalah penambahan nanopartikel $\mathrm{ZrO}_{2}$ konsentrasi $7 \%{ }^{4} \mathrm{Hal}$ tersbut disebabkan karena adanya transfer beban antara nanopartikel $\mathrm{ZrO}_{2}$ dengan matriks polimer saat aplikasi beban dilakukan. Peningkatan kekuatan karena tingginya kekuatan pergeseran permukaan antara nanopartikel dan matriks yang disebabkan oleh adanya pembentukan cross-link atau ikatan supra molekuler yang menutupi butiran nanopartikel sehingga dapat mencegah perluasan cracking. Distribusi nanopartikel $\mathrm{ZrO}_{2}$ memungkinkan partikel-partikel tersebut memasuki kemudian mengisi ruang antara rantai makromolekul linear dari polimer dan gerakan segmental makromolekul juga menjadi terbatas sehingga distribusi nanopartikel lebih efektif dan akhirnya kekuatan dan kekakuan bahan dapat meningkat dan basis gigi tiruan tidak mudah patah. ${ }^{4,5,9,10}$
Pada penelitian ini ditemukan adanya beberapa nilai kekuatan impak kelompok dengan penambahan nanopartikel $\mathrm{ZrO}_{2}$ konsentrasi $7 \%$ lebih rendah dari kelompok kontrol. Hal ini dapat terjadi akibat penambahan nanopartikel yang terlalu banyak dapat menyebabkan defek padta bahan sehingga menurunkan kekuatan bahan, pengendapan partikel-partikel di dalam resin, dan penambahan nanopartikel yang berlebih ketika telah mencapai titik jenuh matriks akan menyebabkan gangguan dalam kontinuitas matriks resin. Hussein K, dkk. (2015) menguji beberapa kelompok konsentrasi nanopartikel $\mathrm{ZrO}_{2}$ terhadap kekuatan impak dan transversal RAPP yang yang terdiri dari beberapa kelompok. Kelompok pertama merupakan kelompok kontrol tanpa penambahan nanopartikel $\mathrm{ZrO}_{2}$, kelompok kedua dengan penambahan nanopartikel $\mathrm{ZrO}_{2} 3 \%$, kelompok ketiga dengan penambahan nanopartikel $\mathrm{ZrO}_{2} 5 \%$, dan kelompok keempat dengan penambahan nanopartikel $\mathrm{ZrO}_{2} 7 \%$. Hasil penelitian menunjukkan terjadi peningkatan nilai kekuatan transversal yang signifikan pada penambahan nanopartikel $\mathrm{ZrO}_{2}$ dengan konsentrasi $3 \%$ dan 5\%, namun terjadi penurunan kekuatan pada penambahan nanopartikel $\mathrm{ZrO}_{2}$ dengan konsentrasi $7 \%$ dibanding kelompok kontrol.

\section{KESIMPULAN}

Berdasarkan hasil penelitian diatas, dapat disimpulkan bahwa penambahan nanopartikel $\mathrm{ZrO}_{2}$ konsentrasi 5\% dan 6\% dapat meningkatkan kekuatan impak dan transversal dari basis gigi tiruan RAPP, tetapi penambahan nanopartikel $\mathrm{ZrO}_{2}$ konsentrasi $5 \%$ lebih baik dibandingkan penambahan nanopartikel $\mathrm{ZrO}_{2}$ konsentrasi $6 \%$, namum terjadi penurunan kekuatan impak dan transversal dengan penambahan nanopartikel $\mathrm{ZrO}_{2}$ konsentari $7 \%$ pada bahan basis gigi tiruan RAPP.

\section{DAFTAR PUSTAKA}

1. Annusavice KJ. Buku ajar ilmu bahan kedokteran gigi. Alih Bahasa. Johan Arif Budiman. Jakarta : EGC, 2003:49-52, 59, 177235.

2. Powers JM, Sakaguchi RL. Craig's restorative dental materials. $12^{\text {nd }}$ ed. Missouri: Elsevier, 2006: 513-546.

3. Wilson HJ, Mansfield MA, Health JR, Spence D. Dental technology and materials for student. $8^{\text {th }}$ Edition. Oxford: Blackwell Scientific Publication, 1987: 352-371.

4. Ihab NS, Moudhaffar M. Evaluation the effect of modified nano-fillers adition on some properties of heat cured acrylic denture base material. J Bagh College Dent 2011; 23(3): 239.

5. Hammed HK, Rahman HA. The effect of addition nano particle $\mathrm{ZrO}_{2}$ on some properties of autoclave processed heat cure acrylic denture base material. J Bagh College Dent 2015; 27(1): $32-9$ 
6. Aljafery AMA, Basima MAH. Effect of addition $\mathrm{ZrO}_{2}-\mathrm{Al}_{2} \mathrm{O}_{3}$ nanoparticles mixture on some properties and denture base adaptation of heat cured acrylic resin denture base material. J Bagh College Dent 2015; 27(3): 1-7.

7. Ahmed MA, Ebrahim MI. Effect of zirconium oxide nano-fillers addition on the flexural strength, fracture toughness, and hardness of heat-polymerized acrylic resin.. WJNSE 2014; 4: $50-7$

8. Ravindranath, Sabarigirinathan C, Vinayagavel, dkk. A comparative study to evaluate the mechanical properties zirconium oxide added polymethil methacrylate by two different concentration - in vitro study. Ann Int Med and Dent Res 2015; 1(3): 161-65.

9. Asopa V, Suresh S. A comparative evaluation of properties of zirconia reinforced high impact acrylic resin with that of high impact acrylic resin. The Saudi Journal for Dental Research 2015; 6: 146-151.

10. Gad M, Arrejaie AS, Halim MSA, dkk. The reinforcement effect of nano-zirconia on the transverse strength of repaired acrylic denture base. Int Journal of Dent 2016; 1-6.
11. Madfa AA, Al-Sanabani F, Al-Qudami NH, dkk. Use of zirconia in dentistry: an overview. The Open Bio Material J 2014; 5: 1-9

12. Takano T, Sakurai K. Overview of zirconia: application as denture base material substituting for metal. Int J of Pros and Res Dent 2013; 3(4): 153-56

13. Volpato CAM, Gustavo LD, Garbelloto A, dkk. Application of zirconia in dentistry: biological, mechanical and optical considerations. (0 $\underline{6}$ September 2011).

14. Salman TA, Khalaf HA. The influence of adding of modified $\mathrm{ZrO}_{2}-\mathrm{TiO}_{2}$ nanoparticles on certain physical and mechanical properties of heat polymerized acrylic resin. J Bagh College Dent 2015; 27(3): 33-9.

15. Ferasima R. Pengaruh penambahan serat kaca dan serat polietilen terhadap kekuatan impak dan transversal pada bahan basis gigi tiruan resin akrilik polimerisasi panas. IDJ 2013; 2 (1): 27-36.

16. Vojvodic D, Matejicek F, Schauperl dkk. Flexural strength of e-glass fiber reinforced dental polymer and high impact strength resin. Strojarstvo 2008; 50 (4): 221-3. 